Archive for

Organic Chemistry

Arkivoc 2020, part iii, $120-135$

\title{
Microwave-Assisted oxidation reaction of primary alcohols with sensitive functional groups to aldehydes using Ruthenium Diphosphorus Complexes
}

\author{
Thashree Marimuthu, Saba Alapour, and Holger B. Friedrich*
}

Catalysis Research Group, School of Chemistry and Physics, University of KwaZulu-Natal, Westville campus, Durban, 4000, South Africa

Email: friedric@ukzn.ac.za

Received 03-17-2020

Accepted 09-15-2020

Published on line $09-25-2020$

\section{Abstract}

Microwave-assisted oxidation of primary alcohols to aldehydes is described using complexes with bidentate diphosphorus-xanthene ligands coordinated to $\mathrm{Ru}$. The reactions took place readily at $120{ }^{\circ} \mathrm{C}$ with $1 \mathrm{~mol} \%$ catalyst loading that was generated in situ from the added $\left[\mathrm{Ru}(\mathrm{H})_{2}\left(\mathrm{PPh}_{3}\right)_{3}(\mathrm{CO})\right]$ and diphosphine ligands. The aldehyde yields for the benzylic alcohols were in the range $50-100 \%$, while aliphatic alcohols gave yields of 4874\%. For the first time, oxidation reactions under solvent-free conditions using these ligands are also presented, making the reaction greener. Other metals were also tested, and it was found that changing the metal center to Ir, Rh, or Os results in complexes that showed minimal or no activity towards the desired product.

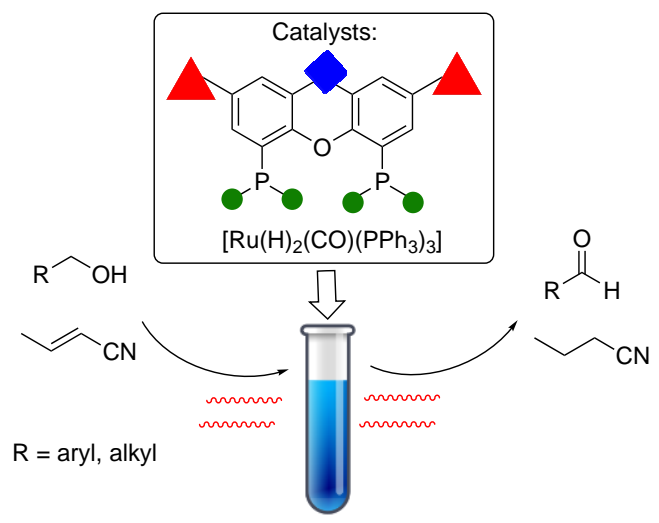

Keywords: Ruthenium Complexes; diphosphorus ligands; oxidation of alcohols to aldehydes; microwaveassisted reactions 


\section{Introduction}

Diphosphorus linked by a single atom gives chelating ligands with small bite-angles, in addition to enabling access to other properties, such as enhancing bridging modes and hemilability. Their use in catalysis has been significant over the last few of years as researchers have applied the properties of these ligands with small bite-angle to a broad number of catalytic reactions. ${ }^{1}$

Ruthenium-based complexes represent a versatile group of catalysts that are important in various organic transformations. ${ }^{2-6}$ Ru-xantphos complexes, for example, have been successfully employed in hydrogenation and $\mathrm{C}-\mathrm{C}$ bond coupling reactions. ${ }^{7,8}$ As a part of our ongoing study of xanthene transition metal complexes, ${ }^{8,9}$ we report here the application of these ligands in the Ru-catalysed oxidation of primary alcohols to aldehydes. The oxidation reaction is one the most fundamental reactions in synthetic organic chemistry and has been the subject of numerous studies. ${ }^{10-17}$ Ruthenium is a well stablished metal for the oxidation of alcohols. ${ }^{11,18}$ Aldehydes, as a result of their increased electrophilic nature, are more reactive and suitable for a broader range of transformations than the precursor alcohols. ${ }^{19}$ These carbonyl compounds are the building blocks in manufacturing many high value commodities. Therefore, the development of improved catalytic protocols in this area is of interest. Moreover, the oxidation of primary alcohols is a key step in the activation of alcohols via the borrowing hydrogen strategy. ${ }^{20}$ In this approach (Scheme 1), an alcohol is temporarily converted into an aldehyde that is functionalised and then reduced in situ to a higher value or more reactive product. The development and improvement of protocols for this key oxidation step can be used to further optimise borrowing hydrogen strategies.

To the best of our knowledge, there is no report on using the xanthene family ligands for the oxidation of alcohols to aldehydes. A communication by Owston et al. reported the conversion of primary alcohols to methyl esters via an aldehyde intermediate with a $\left[\mathrm{Ru}(\mathrm{xantphos})(\mathrm{H})_{2}\left(\mathrm{PPh}_{3}\right)(\mathrm{CO})\right]$ catalyst. ${ }^{21}$

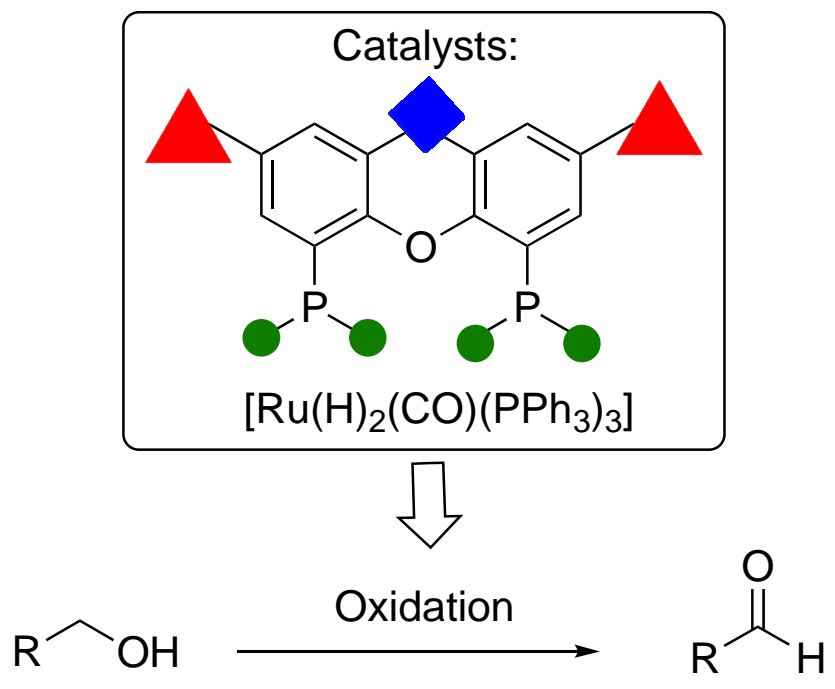

Scheme 1. The oxidation of alcohols to aldehydes using ruthenium diphosphorus complexes. 


\section{Results and Discussion}

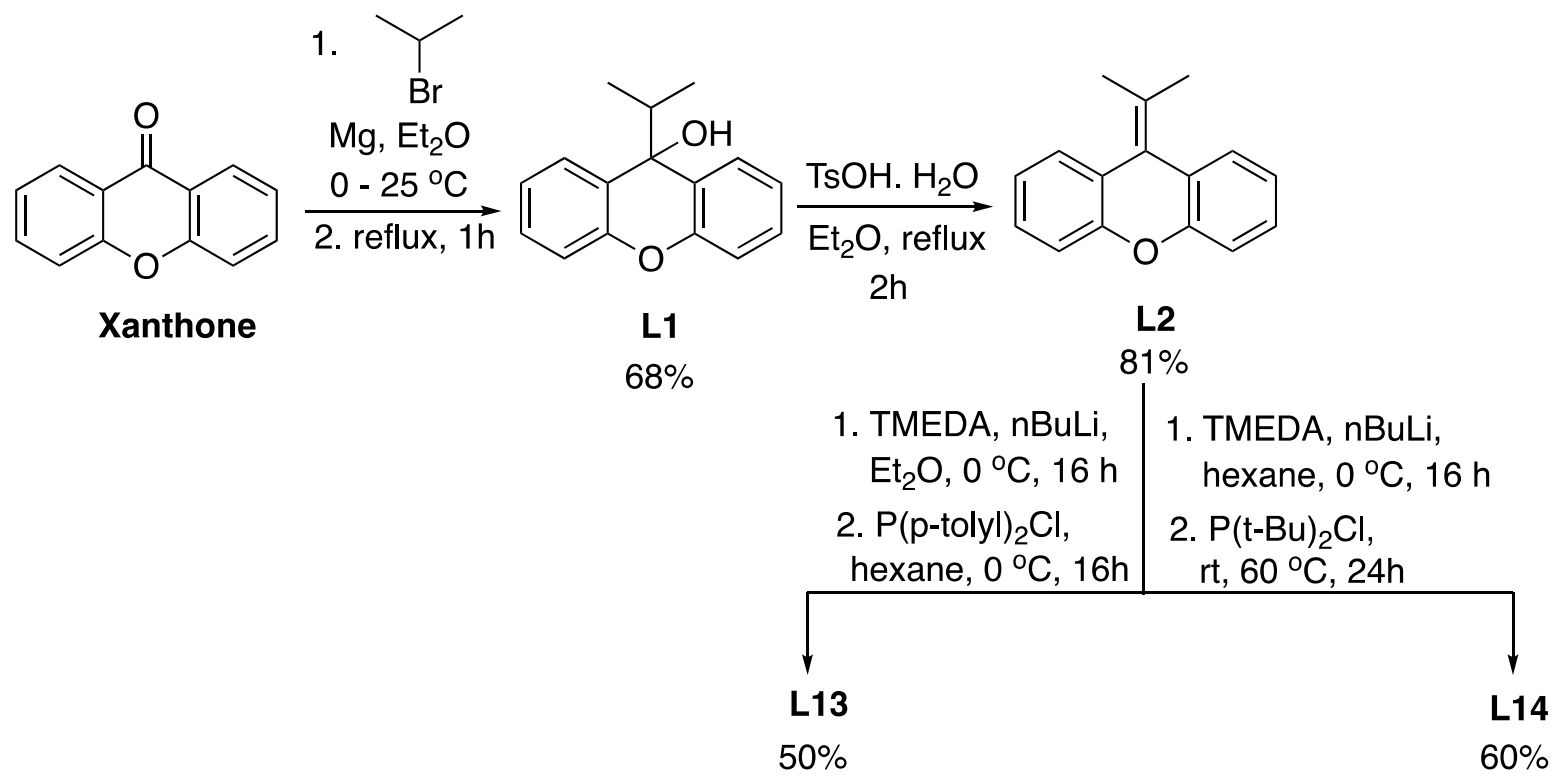

Scheme 2. Synthesis of ligands L13 and L14. (TMEDA=Tetramethylethylenediamine).<smiles>[Y]c1cc([Y])c2c(c1)Oc1c([R6])cc([Y])cc1[X]2P</smiles>

L3. (PDEphos) $\mathrm{X}=-, \mathrm{Y}=\mathrm{H}, \mathrm{R}=\mathrm{Ph}$

L4. (Phosxantphos) $X=P(P h), Y=H, R=P h$

L5. (PTEphos) $\mathrm{X}=-\mathrm{Y}=\mathrm{Me}, \mathrm{R}=\mathrm{Ph}$

L6. (Sixantphos) $X=\mathrm{SiMe}_{2}, \mathrm{Y}=\mathrm{H}, \mathrm{R}=\mathrm{Ph}$

L7. (Thixantphos) $X=S, Y=M e, R=P h$

L8. (Xanthphos) $\mathrm{X}=\mathrm{CMe}_{2}, \mathrm{Y}=\mathrm{H}, \mathrm{R}=\mathrm{Ph}$

L9. (Isopropxantphos) $\mathrm{X}=\mathrm{C}=\mathrm{CMe}_{2}, \mathrm{Y}=\mathrm{H}, \mathrm{R}=\mathrm{Ph}$

L10. (Nixantphos) $\mathrm{X}=\mathrm{NH}, \mathrm{Y}=\mathrm{H}, \mathrm{R}=\mathrm{Ph}$

L11. (Hexantphos) $\mathrm{X}=\mathrm{CMe}_{2}, \mathrm{Y}=\left(\mathrm{CH}_{2}\right)_{5} \mathrm{Me}, \mathrm{R}=\mathrm{Ph}$

L12. (DBFphos) $\mathrm{X}=-, \mathrm{Y}=\mathrm{H}, \mathrm{R}=\mathrm{Ph}$

L13. (Ipxtolylphos) $\mathrm{X}=\mathrm{C}=\mathrm{CMe}_{2}, \mathrm{Y}=\mathrm{H}, \mathrm{R}=p$-tolyl

L14. (Ipxbutylphos) $\mathrm{X}=\mathrm{C}=\mathrm{CMe}_{2}, \mathrm{Y}=\mathrm{H}, \mathrm{R}=t$-butyl

Figure 1. Ligands that were investigated in this study.

\section{Ligand Synthesis}

Ligand synthesis involved preparation of the backbone, followed by functionalisation with the diphosphine moiety. The presence of the ether linkage allows for the regiospecific lithiation of the backbone (Scheme 2). ${ }^{22-}$ 24 This selective lithiation directs the electrophilic attack of the phosphorus source and favours the functionalisation of the backbone with the phosphorus donors. All ligands were prepared via few steps and were easily recrystallized from suitable solvents. The ligands (L3-L14) prepared for this work are presented in 
Figure 1.

The parent compound xantphos (L8) is obtained when $\mathrm{X}=\mathrm{C}\left(\mathrm{CH}_{3}\right)_{2}, \mathrm{Y}=\mathrm{H}$, and $\mathrm{R}=\mathrm{Ph}$. Different donors of varying atomic sizes were introduced at the $X$ position to investigate homologous ligands with subtle changes in the bite angle. The introduction of such donors contributes to variations in electronic effects in the backbone. It is important to note that the $X$ donor atoms are too far removed from the diphosphine pincer atoms to electronically influence their coordination chemistry, e.g. to transition metals. Variations at positions $a$ and $b$ gave rise to the xanthene related ligands L3, L5 and L12. For some of the studied ligands, the environment around the chelating phosphorus donors (R) was also varied to determine the effect of such changes on the bite angle and reactivity. For example, bulky $t$-butyl groups were employed to induce a steric effect at the phosphorus donors, whereas a strong electron-donating $p$-tolyl group was used to induce an electronic effect.

For the synthesis of ligand L13 and L14, the backbone was prepared using the reaction route presented in Scheme 2. This involved a Grignard reaction, ${ }^{25}$ followed by a dehydration reaction on $\mathbf{L 1}$ to give backbone $\mathbf{L} \mathbf{2}$ (Scheme 2). Initially, $\mathrm{H}_{2} \mathrm{SO}_{4}$ and trifluoroacetic acid were investigated as dehydrating agents. However, the use of $p$-toluenesulfonic acid monohydrate $\left(\mathrm{TsOH} . \mathrm{H}_{2} \mathrm{O}\right)$ gave the highest yield. One-pot lithiation of $\mathbf{L} 2$, followed by addition of phosphorus reagent yielded $\mathbf{L 1 3}^{26}$ and $\mathbf{L} 14 .{ }^{27}$

\section{Optimization for catalyst testing}

It has been established that the use of microwave energy for organic synthesis can result in shorter reaction times and improved yields as compared to conventional heating. ${ }^{28-30}$ On this basis, we decided to examine the oxidation of alcohols to aldehydes under microwave irritation conditions, initially examining the oxidation of benzyl alcohol (1a) to benzaldehyde (2a). Using a modified laboratory microwave, in situ complexation of $\left[\mathrm{Ru}(\mathrm{H})_{2}(\mathrm{CO})\left(\mathrm{PPh}_{3}\right)_{3}\right]$ with Xantphos was carried out at $80^{\circ} \mathrm{C}$ for $15 \mathrm{~min}$ (power $100 \%$ ), and the catalytic reaction was then allowed to proceed at the same temperature. A yield of $72 \%$ of $2 \mathrm{a}$ was obtained after 10 min as compared to the $4 \mathrm{~h}$ required to achieve a comparable yield using conventional heating (Table 1 , entries 1,2 ). In initial optimisation experiments, the catalyst loading was decreased from 2.5 mol\% to 1 mol\%. This decrease in the catalyst loading resulted in a reduction of the yield of $2 a$ to $30 \%$ after 10 min. However, with the same 1 mol\% of catalyst, a 75\% yield was obtained after $25 \mathrm{~min}$. The catalyst loading was then further decreased to $0.5 \mathrm{~mol} \%$ with a corresponding yield of $63 \%$ of $\mathbf{2 a}$ in the same $25 \mathrm{~min}$ (Table 1, entries 3-5).

After the initial optimisation studies, reaction conditions of catalyst loading of 2.5 mol\%, reaction time of 25 min, toluene as solvent, the substrate to crotononitrile [to scavenge the generated $\mathrm{H}_{2}$ during the reaction] ratio of 1 : 1.5, and temperature of $120{ }^{\circ} \mathrm{C}$ were used for further investigations. In the absence of crotononitrile, no conversion of 1a was observed, confirming that the reaction requires the hydrogen formed to be scavenged by crotononitrile to drive the reaction forward (Table 1 , entry 6 ).

Additional validation and optimisation studies were performed on the catalytic system. Two blank runs were performed to determine the validity of the organometallic catalysis, where no product was formed in the absence of the catalysts that included both ligand and the metal source (Table 1, entries 7 and 8 ). A 95\% yield of 2a was obtained for the Ru-xantphos catalyst (Table 1, Entry 9).

A series of catalyst precursors based on the late row transition metals were screened for this reaction. It was found that changing the metal center to Ir, Rh, or Os results in complexes that showed minimal or no activity towards 1a (Table 1. Entries 10-12). Both Ru and Os complexes display a wide range of oxidation states and are expected to show similar activity for the oxidation reactions. ${ }^{31,32}$ Therefore, we did not anticipate the poor activity observed for the Os analogue (Table 1, entry 10). This lack of activity could be explained by the difference in coordination mode of the Os-xantphos catalyst to the one for Ru-xantphos. Asensio et al. ${ }^{33}$ 
reported the single crystal X-ray data of an Os-xantphos complex, where ortho-metallation to the ether bridge has occurred. In addition, soft Os(II) species tend to bind to soft functional groups, such as the alkene $(C=C)$ in crotononitrile. The preference of Os complexes for direct ligand coordination or metal-carbon bond formation could possibly account for the observed poor activity in this catalytic application.

Ir and Rh complexes are well known for their applications in reduction or hydrogenation type reactions. A decrease in activity relative to the Ru complexes for this 'inverse' reaction was anticipated; however, the extent of their inertness was unexpected. Based on these findings, only Ru-based complexes were subsequently used for all oxidation studies.

To investigate solvent and temperature effects, the conversion of 1a with Ru and ligand L13 was investigated under different conditions (Table 1, entries 13-17). In the context of microwave assisted reactions, xylene behaves similarly to toluene, as these solvents possess similar dielectric parameters. ${ }^{34}$ The use of the less volatile xylene allows the reaction temperature to be increased to $140{ }^{\circ} \mathrm{C}$ to investigate the effect of temperature in this reaction. Average conversion of $94 \%$ over three runs was obtained in xylene at $120^{\circ} \mathrm{C}$. This compares well to the $94 \%$ obtained using toluene (Table 1, entry 13 ). At $140{ }^{\circ} \mathrm{C}$, a correspondingly higher yield of $99 \%$ aldehyde was obtained, (Table 1, entry 14). This suggests that despite the inefficient coupling of xylene and toluene with the energy source, the net effect of the increased reaction temperature and microwave irradiation is so significant that an increase in reaction rate and yield is still noticeable. This further supports that the reaction could successfully be done under solvent-free conditions.

Indeed, outstanding catalytic results were obtained under all solvent-free conditions. The yields were comparable to, and in some cases even better than, the results obtained using xylene and toluene as solvents. The solvent-free oxidation was carried out at three different temperatures (Table 1, entries 15-17), where the obtained yields were 95,96 and 98 percent at 100,120 and $140{ }^{\circ} \mathrm{C}$, respectively. These results suggest that for substrates that are able to act as both the reagent and homogeneous medium, the solvent has minimal or no effect on the reactivity, which is highly desirable. ${ }^{35}$ Increased catalyst efficiency under solvent free conditions is also due to concentration, with the higher concentration increasing the chance for molecular collision and, hence, better conversions were achieved. Therefore, the catalytic results presented and discussed previously can in most cases be interpreted in a solvent-free context, depending on the melting point of the substrate.

In an extended study of the catalytic activity as a function of time, the yield of $1 \mathrm{a}$ was examined under different solvent-free conditions (Figure 2). As the temperature increases, the expected increase in the yield to aldehyde as a product is observed, with the reaction approaching maximum yield after $30 \mathrm{~min}$ at all three chosen temperatures. The difference in yield between the data at $100{ }^{\circ} \mathrm{C}$ and $120^{\circ} \mathrm{C}$ is greater than for $120^{\circ} \mathrm{C}$ and $140{ }^{\circ} \mathrm{C}$. This suggests that a further increase in temperature from $140{ }^{\circ} \mathrm{C}$ will not significantly increase the aldehyde yield or shorten the reaction time. 
Table 1. Optimisation study on the oxidation of $\mathbf{1 a}$ to $\mathbf{2 a}$

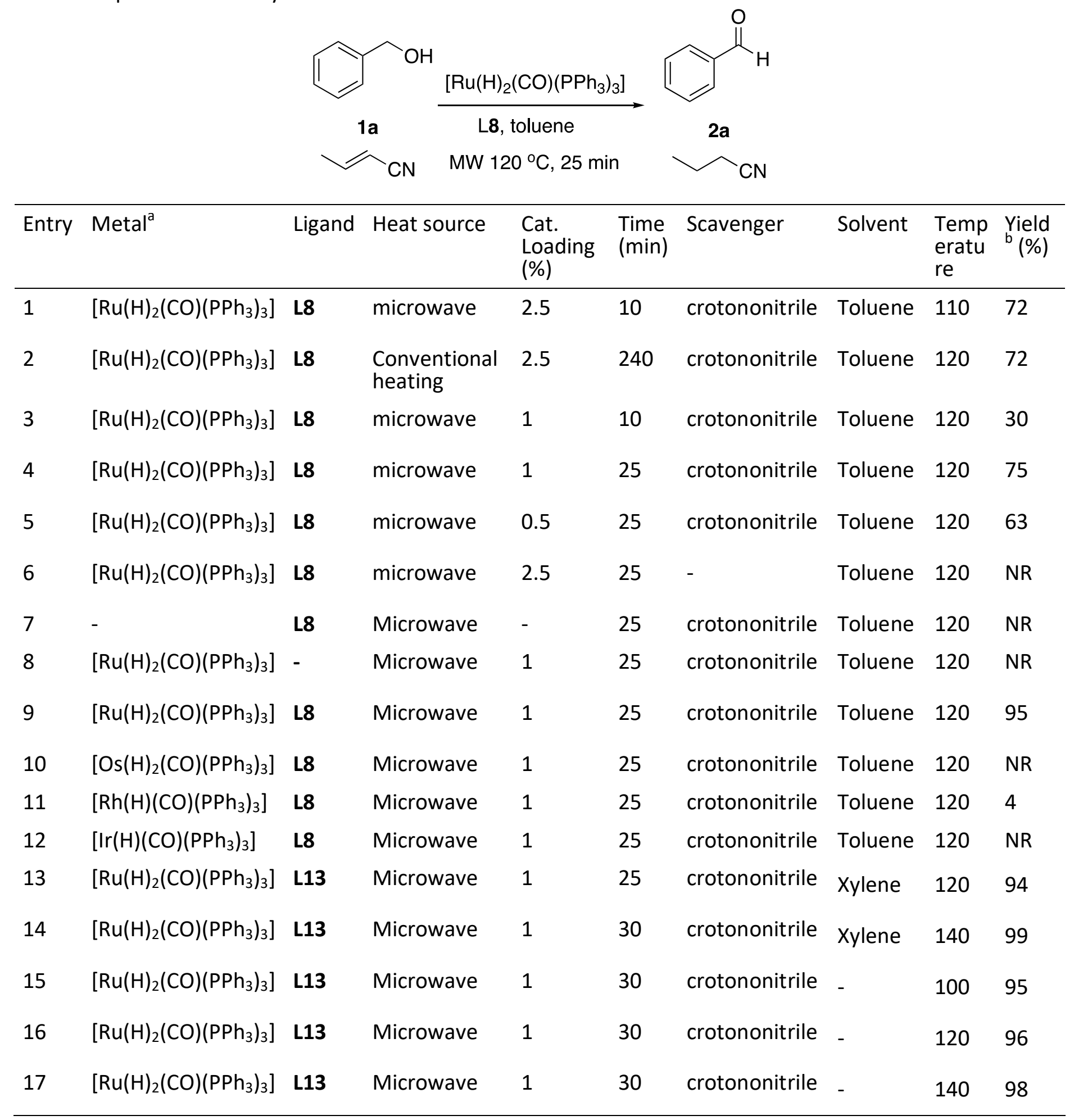

\footnotetext{
${ }^{a}$ Complexation $=15 \mathrm{~min}$ at $80^{\circ} \mathrm{C} .{ }^{b}$ Yields determined by ${ }^{1} \mathrm{H} \mathrm{NMR}$.
} 


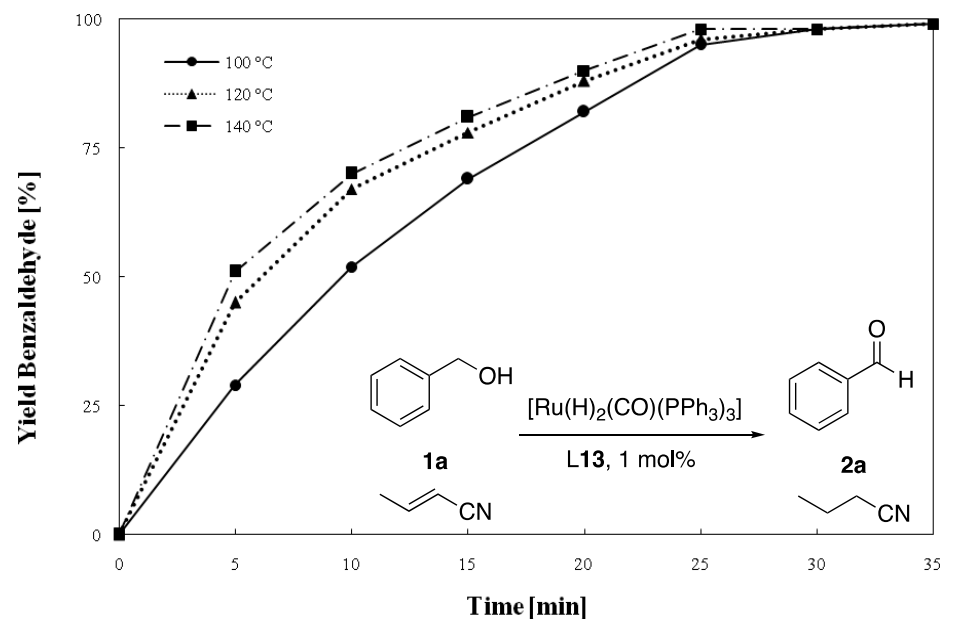

Figure 2. Catalytic activity over the time for the solvent-free oxidation of benzyl alcohol.

\section{Catalytic testing and study on the effect of bite angle}

The ligands prepared for this work are presented in Table 2. The parent ligand, xantphos (L8), is obtained with $X=C\left(C_{3}\right)_{2}, Y=H$, and $\mathrm{R}=\mathrm{Ph}$ attached to the side chains. Different donors having varied atomic sizes were introduced at the $\mathrm{X}$ position to investigate homologous ligands with subtle changes in the bite angle.

Variations at positions $a$ and $b$ gave rise to the xanthene related ligands L3, L5 and L12. The environment around the chelating phosphorus donors $(R)$ was also varied to determine the effect of such changes on the bite angle and also reactivity for the chosen catalytic model. For example, bulky $t$-butyl groups were employed to induce a steric hinderance effect at the phosphorus donors, whereas a strong electron-donating $p$-tolyl group was used to induce an electronic (inductive) effect. The structures of the synthesised ligands were determined by ${ }^{1} \mathrm{H}$ NMR, ${ }^{13} \mathrm{C} N M R,{ }^{31} \mathrm{P} N M R$ and HR-MS and in some cases further confirmed by X-ray crystallography where the crystal of the targeted compound was successfully grown (L13). ${ }^{8}$

The various xanthene type ligands L3-L14 were then tested in the oxidation reaction under the optimised reaction conditions (Table 2). Surprisingly, in comparison to most of the catalytic results using xanthene family ligands reported by van Leeuwen and co-workers, ${ }^{36-39}$ there is no obvious correlation between the observed reactivity and natural bite angle. Similarly, most xanthene family ligands (L4, L6- L11) were active for this reaction, with no obvious trend between measured bite angle and catalytic activity. However, ligands L3, L5 and L12 performed poorly when compared to xantphos.

Ligands L4 and $\mathbf{L 9}$ gave improved catalytic performance relative to the benchmark ligand, $\mathbf{L} 8$. The effect of the xanthene backbone was apparent on the results obtained for L4 and L5. Both these ligands (L4 and L5) have essentially identical bite angles, yet remarkably different activity was observed (Table 2, entries 2-3). The flexibility of the backbone in ligand $\mathbf{L} \mathbf{5}$ and $\mathbf{L} \mathbf{3}$ could possibly account for the poor activity. Ligands L6, L7, $\mathbf{~} \mathbf{8}$ exhibited similar activity, suggesting that electronic changes in the backbone do not significantly affect the reactivity for this particular reaction (Table 2, entries 4-6). The $\mathbf{N}$ donor ligand $\mathbf{L} \mathbf{1 0}$ gave the lowest yields to $\mathbf{2 a}$ for the xanthene family ligands (14\%), significantly lower than for $\mathbf{L} 8$ (Table 2, entries 6 and 8). The poor reactivity for this family of ligands is possibly due to weak interactions between the amine in the phenoxazine ring and the metal centre. Similar poor results for $\mathbf{L 1 0}$ relative to other xanthene family ligands have been reported in $\mathrm{C}-\mathrm{C}$ bond formation reactions. ${ }^{40}$ 
Table 2. Investigation of ligand electronic and steric properties effect on oxidation $1 \mathrm{a}$ to $2 \mathrm{a}$ at $120{ }^{\circ} \mathrm{C}$ for 25 min. (Microwave)

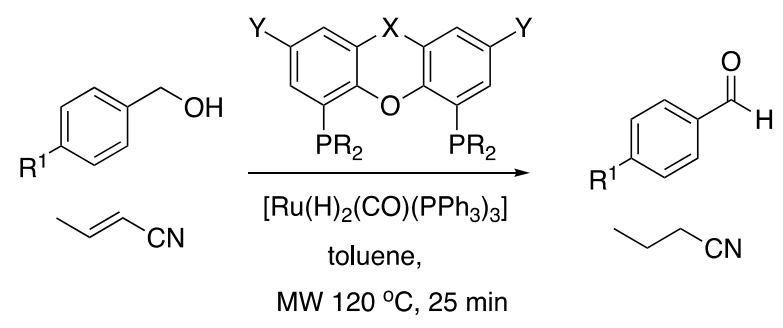

\begin{tabular}{|c|c|c|c|c|c|c|c|c|}
\hline No & Ligand $^{\mathrm{a}}$ & $x$ & $\mathrm{Y}$ & $\mathrm{R}$ & $\begin{array}{l}\text { Bite angle } \\
\left(\beta n^{\circ}\right)\end{array}$ & $\mathrm{R}^{1}$ & $\begin{array}{l}\text { Cat. } \\
\text { Loading } \\
(\%)\end{array}$ & $\begin{array}{l}\text { Yield } \\
(\%)\end{array}$ \\
\hline 1 & DPEphos (L3) & - & $\mathrm{H}$ & $\mathrm{Ph}$ & $102.2^{b}$ & $\mathrm{H}$ & 1 & 18 \\
\hline 2 & Phosxantphos (L4) & $\mathrm{P}(\mathrm{Ph})$ & $\mathrm{H}$ & $\mathrm{Ph}$ & $107.9^{c}$ & $\mathrm{H}$ & 1 & 91 \\
\hline 3 & PTEphos (L5) & - & $\mathrm{Me}$ & $\mathrm{Ph}$ & $108.0^{a}$ & $\mathrm{H}$ & 1 & 11 \\
\hline 4 & Sixantphos (L6) & $\mathrm{SiMe}_{2}$ & $\mathrm{H}$ & $\mathrm{Ph}$ & $108.5^{c}$ & $\mathrm{H}$ & 1 & 87 \\
\hline 5 & Thixantphos (L7) & S & Me & $\mathrm{Ph}$ & $109.6^{c}$ & $\mathrm{H}$ & 1 & 86 \\
\hline 6 & Xantphos (L8) & $\mathrm{CMe}_{2}$ & $\mathrm{H}$ & $\mathrm{Ph}$ & $111.4^{c}$ & $\mathrm{H}$ & 1 & 83 \\
\hline 7 & Isopropxantphos (L9) & $\mathrm{C}=\mathrm{CMe}_{2}$ & $\mathrm{H}$ & $\mathrm{Ph}$ & $113.2^{c}$ & $\mathrm{H}$ & 1 & 92 \\
\hline 8 & Nixantphos (L10) & $\mathrm{NH}$ & $\mathrm{H}$ & $\mathrm{Ph}$ & $114.2^{c}$ & $\mathrm{H}$ & 1 & 14 \\
\hline 9 & Hexantphos (L11) & $\mathrm{CMe}_{2}$ & $\left(\mathrm{CH}_{2}\right)_{5} \mathrm{Me}$ & $\mathrm{Ph}$ & $116.0^{e}$ & $\mathrm{H}$ & 1 & 77 \\
\hline 10 & DBFphos (L12) & - & $\mathrm{H}$ & $\mathrm{Ph}$ & $131.1^{J}$ & $\mathrm{H}$ & 1 & 8 \\
\hline 11 & Ipxtolylphos (L13) & $\mathrm{C}=\mathrm{CMe}_{2}$ & $\mathrm{H}$ & $p$-tolyl ${ }^{a}$ & $113.1^{\mathrm{e}}$ & $\mathrm{Cl}$ & 1 & 100 \\
\hline 12 & Ipxtolylphos (L13) & $\mathrm{C}=\mathrm{CMe}_{2}$ & $\mathrm{H}$ & $p$-tolyl ${ }^{a}$ & $113.1^{\mathrm{e}}$ & $\mathrm{H}$ & 1 & 95 \\
\hline 13 & Ipxtolylphos (L13) & $\mathrm{C}=\mathrm{CMe}_{2}$ & $\mathrm{H}$ & $p$-tolyl ${ }^{a}$ & $113.1^{\mathrm{e}}$ & $\mathrm{Me}$ & 1 & 81 \\
\hline 14 & Ipxbutylphos (L14) & $\mathrm{C}=\mathrm{CMe}_{2}$ & $\mathrm{H}$ & $t$-butyl $\left.\right|^{a}$ & $137.9^{e}$ & $\mathrm{H}$ & 0.5 & 4 \\
\hline 15 & Isopropxantphos (L9) & $\mathrm{C}=\mathrm{CMe}_{2}$ & $\mathrm{H}$ & $\mathrm{ph}^{c}$ & $113.2^{c}$ & $\mathrm{Cl}$ & 0.5 & 83 \\
\hline 16 & Ipxtolylphos (L13) & $\mathrm{C}=\mathrm{CMe}_{2}$ & $\mathrm{H}$ & $p$-tolyl ${ }^{c}$ & $113.1^{\mathrm{e}}$ & $\mathrm{Cl}$ & 0.5 & 85 \\
\hline
\end{tabular}

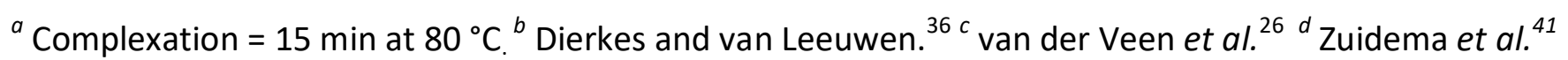
${ }^{e}$ Calculated in this work. ${ }^{42} \mathrm{~K}$ Kranenburg et al. ${ }^{43}$ 
Ligand L14 (Table 2, entry 14) was found to be poorly activating, giving a yield of $4 \%$ towards 1 a. The low yield observed for this ligand is possibly due to the significantly larger natural bite angle preventing the formation of stable chelates. The poor catalytic activity has also been observed for Pd-catalysed cross-coupling reactions involving a similar xantphos analogue of L14. ${ }^{27}$ Ligands L9 and L13 were also found to be active at a lower catalyst loading of 0.5 mol\%, (Table 2, entries 15 and 16). Since using ligand L13 resulted in the best yield towards the desired product (Table 2, Entry 11), and because of its relative ease of synthesis, it was chosen for further investigations.

On the basis of these experiments the scope of the oxidation was studied with different benzylic and aliphatic alcohols using the optimised reaction conditions. The $\left[\mathrm{Ru}(\mathrm{H})_{2}(\mathrm{CO})\left(\mathrm{PPh}_{3}\right)_{3}\right] /$ ligand $\mathbf{L 1 3}$ catalyst showed greater activity for the oxidation of the benzylic alcohol, $\mathbf{1 a}$, than the aliphatics, $\mathbf{1} \mathbf{j}$-1n (Table 3 ). The aldehyde yields for the benzylic alcohol substrates (Table 3) ranged from 50-100\%. These observed results can be rationalised in terms of the electron-withdrawing or -donating nature of the substrates relative to 1a. 1-Naphtyl methanol 1b was only partially oxidised to give a yield of $79 \%$. This is possibly due to an increase in the bulkiness of the substrate in comparison to $\mathbf{1 a}$. The substrates $\mathbf{1 c}$ - $\mathbf{h}$ (except for $\mathbf{1 g}$ ) with various electron-withdrawing groups (Table 3). The strongest electron deficient substrate 4-nitrobenzyl alcohol (1c) underwent partial oxidation with an observed yield of nitrobenzaldehyde of $50 \%$. This was expected as the nitrogen atom has a lone pair of electrons and can deactivate the phenyl ring, thus retarding the oxidation of $\mathbf{1 c}$. This suggests that the extent of the electron-withdrawing nature strongly influences the reactivity towards the aldehyde product.

Compared to 4-fluorobenzyl alcohol (1d), 4-chlorobenzyl alcohol (1e) is less electron deficient as the $\mathrm{Cl}$ atom is less electronegative than $\mathrm{F}$. Therefore, it was expected that the oxidation of $1 \mathrm{e}$ would be easier than 1d. 4chlorobenzaldehyde (2e) was obtained quantitatively, suggesting that the electronic environment of this substrate was ideal for this catalytic system. Entries 7-8 account for substrates that are electron rich relative to 1 a. A $93 \%$ yield was obtained for 4-methoxy benzaldehyde (19) due to the strong electron-donating effect of the methoxy group. The relatively weaker, or moderately electron rich substrate, 4-methylbenzyl alcohol (1h) presented lower yields of $60 \%$.

The reaction did not proceed in the case of $\mathbf{1 i}$, possibly due to the chelation effect of the nitrogen donor in the pyridine ring. Slatford et al. have reported similar poor activity for a furfuryl alcohol substrate due to the chelation of the $\mathrm{O}$ donor in the furfuryl group. ${ }^{44}$ The aldehyde yield for the aliphatic alcohol substrates (1j-n) ranged from 48 to $74 \%$. Cyclohexylmethanol, (1j), was investigated as a structurally similar, less activated analogue of $1 \mathrm{a}$. The aldehyde product was obtained in $43 \%$ yield, showing the effect of the absence of aromaticity on the oxidation reaction.

2-Phenylethanol (1k) shows a lower yield of 74\% compared to $1 \mathbf{a}$, possibly due to the loss of 'benzylic' nature caused by an increase in the chain length of the alkyl linker. A further increase in this alkyl linker chain length resulted in a corresponding drop in product yield for 3-phenylpropan-1-ol (11). The addition of an electrondonating methyl group, in 2-methylphenethyl alcohol (1m), further decreases the yield of desired product, which was contrary the trend observed for the aromatic based ligands discussed above.

Although straight chain aliphatic alcohols are generally more difficult to oxidise, surprisingly, a yield of $67 \%$ was obtained for decanal (2n). This yield could possibly be further optimised by increasing the microwave reaction time or catalyst loading, but to have a correct basis for this comparative study, these variables were kept constant for all substrates. 
Table 3. Oxidation of various alcohols at $120^{\circ} \mathrm{C}$ for $25 \mathrm{~min}$ (microwave) using $\left[\mathrm{Ru}(\mathrm{H})_{2}(\mathrm{CO})\left(\mathrm{PPh}_{3}\right)_{3}\right]$ and ligand 13

\begin{tabular}{|c|c|c|}
\hline Entry & Substrate & Yield (\%) \\
\hline 1 & $\left(\mathrm{C}_{6} \mathrm{H}_{5}\right) \mathrm{CH}_{2} \mathrm{OH}(1 \mathrm{a})$ & 92 \\
\hline 2 & (naphthyl) $\mathrm{CH}_{2} \mathrm{OH}$ (1) & 79 \\
\hline 3 & 4- $\mathrm{NO}_{2}\left(\mathrm{C}_{6} \mathrm{H}_{4}\right) \mathrm{CH}_{2} \mathrm{OH}(\mathbf{1 c})$ & 50 \\
\hline 4 & $4-\mathrm{F}\left(\mathrm{C}_{6} \mathrm{H}_{4}\right) \mathrm{CH}_{2} \mathrm{OH}(1 \mathrm{~d})$ & 60 \\
\hline 5 & $4-\mathrm{Cl}\left(\mathrm{C}_{6} \mathrm{H}_{4}\right) \mathrm{CH}_{2} \mathrm{OH}(1 \mathrm{e})$ & 100 \\
\hline 6 & $4-\mathrm{CF}_{3}\left(\mathrm{C}_{6} \mathrm{H}_{4}\right) \mathrm{CH}_{2} \mathrm{OH}$ (1f) & 58 \\
\hline 7 & 4-OMe $\left(\mathrm{C}_{6} \mathrm{H}_{4}\right) \mathrm{CH}_{2} \mathrm{OH}(\mathbf{g})$ & 93 \\
\hline 8 & 4-Me $\left(\mathrm{C}_{6} \mathrm{H}_{4}\right) \mathrm{CH}_{2} \mathrm{OH}$ (1h) & 60 \\
\hline 9 & (3-Py) $\mathrm{CH}_{2} \mathrm{OH}(1 \mathrm{i})$ & NR \\
\hline 10 & (cyclohexyl) $\mathrm{CH}_{2} \mathrm{OH}(\mathbf{1 j})$ & 43 \\
\hline 11 & $\left(\mathrm{C}_{6} \mathrm{H}_{5}\right) \mathrm{CH}_{2} \mathrm{CH}_{2} \mathrm{OH}(\mathbf{1 k})$ & 74 \\
\hline 12 & $\left(\mathrm{C}_{6} \mathrm{H}_{5}\right) \mathrm{CH}_{2} \mathrm{CH}_{2} \mathrm{CH}_{2} \mathrm{OH}$ (1I) & 58 \\
\hline 13 & 1-Me $\left(\mathrm{C}_{6} \mathrm{H}_{4}\right) \mathrm{CH}_{2} \mathrm{CH}_{2} \mathrm{OH}(1 \mathrm{~m})$ & 48 \\
\hline 14 & 1-decanol (1n) & 67 \\
\hline 15 & cinnamyl alcohol (10) & 72 \\
\hline 16 & 4-OMe-cinnamyl alcohol (1p) & 55 \\
\hline
\end{tabular}

The oxidation of allylic alcohols 10-p gave lower yields relative to $\mathbf{1 a}$, but with no observable alkene isomerisation, which highlights the successful application of this catalyst for selective oxidation of different alcohols containing sensitive functionalities. For cinnamyl alcohol (10) a yield of $72 \%$ to the corresponding product was obtained. The results obtained suggests that the redox properties of the metal centre is very sensitive to the electronic properties of the substrate as well as the applied ligand. An alteration of the electronic environment by introducing a $\mathrm{sp}^{2}$ carbon in the alkene bond could account for the increased product yield for $\mathbf{1 0}$ relative to the related substrate in $\mathbf{1}$. In comparison to the parent molecule $\mathbf{1 0}$, a decreased aldehyde yield was observed for $\mathbf{1 p}$. This is likely due to the methoxy group donating electron density and initiating a 'push-pull' effect involving the alkene bond, which renders the aliphatic tail less activated. There was no observed dimerisation of the aldehydes to the esters with the alcohol substrates. As can be seen from the result, the observed reactivity towards the product aldehyde for the Ru-ipxtolylphos, L13, complex was found to be very sensitive to the electronic environment of the substrates. 


\section{Conclusions}

We have demonstrated the successful homogeneous Ru-catalysed oxidation of primary alcohols to aldehydes using xanthene family ligands. Catalytic testing protocols have been developed, implemented and optimised, including the use of microwave irradiation. The use of microwave significantly reduced reaction time and improved yields when compared to conventional heating. In comparison to Rh, Os, and Ir metal centers, Ruxantphos complexes were found to be active for the oxidation of benzyl alcohol. In general, no pronounced correlation between the natural bite angle and reactivity could be discovered, which suggests that this reaction is not bite-angle sensitive. A total of sixteen primary alcohols with different functionalities were oxidized and, the yields of aldehydes range from $50-100 \%$ for benzylic alcohols and from $48-74 \%$ for aliphatic alcohols. The reactivity of these Ru-based catalysts was found to mainly be sensitive to the electronic nature of the substrate. Solvent-free techniques were also examined, and the results obtained were similar or better to those obtained with the solvent.

\section{Experimental Section}

General. All reactions were performed under Ar. All solvents were distilled over an appropriate drying agent according to standard procedures. Di-t-butylchlorophosphine (96\%), di-p-tolylether, 1.6 M solution in hexanes of $n$-butyllithium, xanthone (97\%), were sourced from Sigma-Aldrich. Chlorodiphenylphosphine (97\%) was distilled under vacuum, and stored under Ar. Chloro-di(p-tolyl)phosphine (95\%) was purchased from Alfa Aesar and used without further purification. $N, N, N^{\prime}, N^{\prime}$-tetramethylethylene-diamine (TMEDA, 99\%) was distilled over $\mathrm{LiAlH}_{4}$ and stored under Ar. All metal precursors (except $\left[\mathrm{Rh}(\mathrm{H})(\mathrm{CO})\left(\mathrm{PPh}_{3}\right)_{3}\right]$, Aldrich, 97\%) were prepared by adapted reported methods. ${ }^{21,45}$ NMR spectra were recorded on Bruker AVANCE III $600 \mathrm{MHz}$, and $400 \mathrm{MHz}$ NMR spectrometers. Infrared spectra were recorded on a Perkin Elmer Attenuated Total Reflectance (ATR) spectrometer. Only the significant wavenumbers in $\mathrm{cm}^{-1}$ are reported. High resolution mass spectrometric data were obtained using a Bruker microTOF-Q II instrument operating at ambient temperatures, under electron spray ionisation conditions (ESI), using a sample concentration of approximately $1 \mathrm{ppm}$. Microwave information, calibration and spectral data can be found in the Supporting Information.

Ligands L3, L4, L6-L10, and L12 were prepared according to procedures reported elsewhere. ${ }^{26,36,41,43}$

Preparation of compound L1 (Scheme 2) Mg turnings (2.2 g, $89.2 \mathrm{mmol}$ ) were carefully added in small portions under positive Ar pressure to a solution of 2-bromopropane ( $8.4 \mathrm{~mL}, 89.2 \mathrm{mmol}$ ) in dry $\mathrm{Et}_{2} \mathrm{O}(25 \mathrm{~mL})$ at $0{ }^{\circ} \mathrm{C}$. After $30 \mathrm{~min}$ the solution turned murky white, and once all $\mathrm{Mg}$ turnings were added the reaction was left to stir for $30 \mathrm{~min}$ at $0{ }^{\circ} \mathrm{C}$. Xanthone $(3.5 \mathrm{~g}, 17.8 \mathrm{mmol})$ in $\mathrm{Et}_{2} \mathrm{O}(25 \mathrm{~mL})$ was added portion wise to the chilled reaction mixture. The reaction was warmed and refluxed for $1 \mathrm{~h}$. The reaction was cooled to room temperature, diluted with $\mathrm{Et}_{2} \mathrm{O}(40 \mathrm{~mL})$, and the solution cooled to $0{ }^{\circ} \mathrm{C}$. The reaction was quenched by dropwise addition of a saturated $\mathrm{NH}_{4} \mathrm{Cl}$ solution, filtered, washed with $\mathrm{Et}_{2} \mathrm{O}$ and the organic layer extracted with $\mathrm{Et}_{2} \mathrm{O}\left(3 \times 20 \mathrm{~mL}\right.$ ). After drying over anhydrous $\mathrm{MgSO}_{4}$, filtration and evaporation, the yellow viscous oil was purified by column chromatography on silica gel (hexane/EtOAc, 9:1, $R_{f}=0.5$ ). The product was dried under vacuum to give compound $\mathbf{L} 1$ as white microcrystals: yield: $3.5 \mathrm{~g}(68 \%) ;{ }^{1} \mathrm{H} \mathrm{NMR}\left(\mathrm{CDCl}_{3}, 400 \mathrm{MHz}\right)$

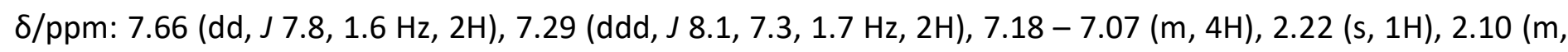
$1 \mathrm{H}), 0.71(\mathrm{~d}, J 6.8 \mathrm{~Hz}, 6 \mathrm{H}) ;{ }^{13} \mathrm{C} \mathrm{NMR}\left(\mathrm{CDCl}_{3}, 101 \mathrm{MHz}\right) \delta / \mathrm{ppm}: 151.0(\mathrm{CO}), 128.6(\mathrm{C}), 126.9(\mathrm{CH}), 126.7(\mathrm{CH})$, $123.0(\mathrm{CH}), 115.8(\mathrm{CH}), 72.1(\mathrm{C}), 42.6(\mathrm{CH}), 16.8\left(\mathrm{CH}_{3}\right)$; IR (neat) v/cm ${ }^{-1}$ 3331, 2981, 2960, 2932, 2874, 1601, 
1575, 1473, 1447, 1020, 1285, 743; HR-MS (ESI): $[\mathrm{M}-\mathrm{OH}]^{+} \mathrm{m} / \mathrm{z}=223.1117$, calcd. for $\mathrm{C}_{16} \mathrm{H}_{15} \mathrm{O} 223.1117$.

Preparation of compound L2 (Scheme 2) To dry DCM (30 mL), L1 (3.0 g, $12.5 \mathrm{mmol})$ was added, and once dissolved two equivalents of $\mathrm{TsOH}_{\mathrm{H}} \mathrm{H}_{2} \mathrm{O}(4.8 \mathrm{~g}, 25.0 \mathrm{mmol})$ were added. The reaction was refluxed for $2 \mathrm{~h}$ and monitored by TLC. The reaction was left to cool to room temperature, deionised water (10 $\mathrm{mL})$ added, and $10 \% \mathrm{NaOH}(15 \mathrm{~mL})$ solution added slowly. The organic layers were extracted with DCM (3 $\times 20 \mathrm{~mL})$. After drying over anhydrous $\mathrm{MgSO}_{4}$, filtration and evaporation, the residue was purified by column chromatography on silica gel (hexane, $\left.100 \%, R_{\mathrm{f}}=0.6\right)$ to give a solid: yield: $2.2 \mathrm{~g}(81 \%) ;{ }^{1} \mathrm{H} \mathrm{NMR}\left(\mathrm{CDCl}_{3}, 400\right.$

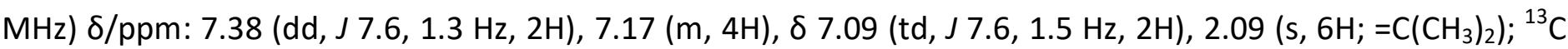
$\mathrm{NMR}\left(\mathrm{CDCl}_{3}, 101 \mathrm{MHz}\right)$ /ppm: 154.2 (CO), 130.7 (C), $128.4(\mathrm{CH}), 127.1(\mathrm{CH}), 126.9$ (C), $122.4(\mathrm{C}), 122.4(\mathrm{CH})$, $116.2(\mathrm{CH}), 23.2\left(\mathrm{CH}_{3}\right)$; IR (neat) v/cm $\mathrm{cm}^{-1} 3067,3035,2938,2905,2852,1595,1471,1441,1250,1211,1195$, 744.

Preparation of ligand L5 At room temperature, di-p-tolylether $(1.0 \mathrm{~g}, 5.0 \mathrm{mmol})$ in THF $(8 \mathrm{~mL})$ was added dropwise to a stirred solution of $n B u L i(7.0 \mathrm{~mL}, 11.1 \mathrm{mmol})$ and TMEDA $(1.7 \mathrm{~mL}, 11.1 \mathrm{mmol})$. The reaction mixture was stirred for $16 \mathrm{~h}$. At room temperature, under a positive flow of argon, $\mathrm{PPh}_{2} \mathrm{Cl}(2.4 \mathrm{~mL}, 11.1 \mathrm{mmol})$ in hexanes $(4 \mathrm{~mL})$ was added dropwise. The beige solution turned yellow and a white precipitate formed. The reaction mixture was left to stir for a further $16 \mathrm{~h}$. DCM $(15 \mathrm{ml})$ and water $(15 \mathrm{ml})$ were added and the reaction mixture stirred rapidly. The aqueous layer was extracted with DCM $(2 \times 10 \mathrm{~mL})$ and the combined fractions dried over anhydrous $\mathrm{MgSO}_{4}$, filtered, and evaporated to give a viscous green-yellow residue. The crude product was washed with acetone, dried, and recrystalised from DCM/EtOH: yield 1.9g $(67 \%) ;{ }^{1} \mathrm{H} N M R$

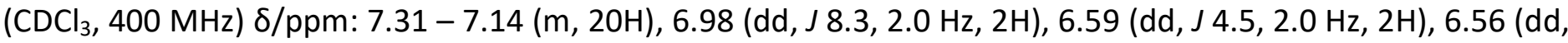
J 8.3, $4.5 \mathrm{~Hz}, 2 \mathrm{H}), 2.14(\mathrm{~s}, 6 \mathrm{H}) ;{ }^{13} \mathrm{C} \mathrm{NMR}\left(\mathrm{CDCl}_{3}, 101 \mathrm{MHz}\right)$ ) $/ \mathrm{ppm}: 157.4(\mathrm{~d}, J(\mathrm{P}, \mathrm{C})=17.5 \mathrm{~Hz}, \mathrm{CO}), 136.8(\mathrm{~d}$, $J(P, C)=11.7 \mathrm{~Hz}$, phenyl C-ipso, PC), $134.2(\mathrm{CH}), 133.8(\mathrm{~d}, J(\mathrm{P}, \mathrm{C})=20.6 \mathrm{~Hz}, \mathrm{CH}$ phenyl), $132.7(\mathrm{C}), 130.8(\mathrm{CH})$, $128.3(\mathrm{CH}), 128.2(\mathrm{dd}, J(\mathrm{P}, \mathrm{C})=8.8,5.3 \mathrm{~Hz}, \mathrm{CHC}-\mathrm{P}), 117.9(\mathrm{CH}), 20.8\left(\mathrm{CH}_{3}\right) ;{ }^{31} \mathrm{P} \mathrm{NMR}\left(\mathrm{CDCl}_{3}, 162 \mathrm{MHz},\right) \delta / \mathrm{ppm}:-$ 16.4; IR (neat) v/cm ${ }^{-1}: 3068,3016,2918,1468,1433,1232,1212,747,736,689 ; \mathrm{HR}-\mathrm{MS}(\mathrm{ESI}):[\mathrm{M}+\mathrm{H}]^{+} \mathrm{m} / \mathrm{z}=$ 567.2000, calcd. for $\mathrm{C}_{38} \mathrm{H}_{33} \mathrm{OP}_{2}$ 567.2001.

Preparation of ligand L11 A solution of 2,7-di-n-hexyl-9,9-dimethylxanthene ( $1 \mathrm{~g}, 2.6 \mathrm{mmol}$ ), and TMEDA (1.0 $\mathrm{mL}, 6.7 \mathrm{mmol})$ in dry degassed $\mathrm{Et}_{2} \mathrm{O}(30 \mathrm{~mL})$ was cooled to $0{ }^{\circ} \mathrm{C}$. To the chilled solution, $n B u L i(4.2 \mathrm{~mL}, 6.7$ $\mathrm{mmol}$ ) was added dropwise. The reaction mixture was allowed to warm to room temperature and left to stir for $16 \mathrm{~h}$. The resulting dark red mixture was cooled to $0{ }^{\circ} \mathrm{C}$ and $\mathrm{PPh}_{2} \mathrm{Cl}(1.3 \mathrm{~mL}, 6.8 \mathrm{mmol})$ in dry hexane $(4 \mathrm{~mL})$ added dropwise. The reaction mixture slowly decolourised and a fine precipitate formed. The reaction was stirred for a further $16 \mathrm{~h}$. The reaction was slowly hydrolysed with a $25 \mathrm{~mL} \mathrm{10 \%} \mathrm{HCl/brine} \mathrm{mixture} \mathrm{(1/1).} \mathrm{The}$ organic layer was removed, and the aqueous layer extracted with DCM. Combined fractions were dried over anhydrous $\mathrm{MgSO}_{4}$, filtered, and evaporated to give a yellow oil. The crude product was washed with hexane (3 $x 10 \mathrm{~mL}$ ), dissolved in DCM, and an equal volume of EtOH added slowly. The solution was left to recrystalise at

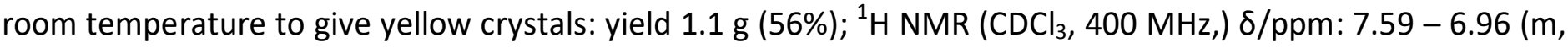
$20 \mathrm{H} \mathrm{P}\left(\mathrm{C}_{6} \mathrm{H}_{5}\right)_{2}$ and $2 \mathrm{H}$ xanthene ring), $6.32(\mathrm{bs}, 2 \mathrm{H}), 2.38(\mathrm{t}, J 7.5 \mathrm{~Hz}, 4 \mathrm{H}), 1.62(\mathrm{~s}, 6 \mathrm{H}), 1.48-0.98(\mathrm{~m}, 16 \mathrm{H}), 0.84$ $(\mathrm{t}, J 6.9 \mathrm{~Hz}, 6 \mathrm{H}) ;{ }^{13} \mathrm{C} \mathrm{NMR}\left(\mathrm{CDCl}_{3}, 101 \mathrm{MHz}\right) \delta / \mathrm{ppm}: 150.9(\mathrm{t}, J(\mathrm{P}, \mathrm{C})=19.6 \mathrm{~Hz}, \mathrm{CO}), 137.7(\mathrm{dd}, J(\mathrm{P}, \mathrm{C})=7.2,5.9$ $\mathrm{Hz}$, phenyl C-ipso, PC), 137.1 (C), 133.9 (t, J (P,C) = 10.4 Hz, CH phenyl), $131.9(\mathrm{CH}), 129.5$ (C), $128.0-128.5$ (m, $\mathrm{CH}$ phenyl), $126.2(\mathrm{CH}), 125.1$ (dd, J 10.6, $2.4 \mathrm{~Hz}, \mathrm{CHC}-\mathrm{P}), 35.3\left(\mathrm{CH}_{2}\right), 31.9\left(\mathrm{CH}_{3}\right), 31.6\left(\mathrm{CH}_{2}\right), 31.2\left(\mathrm{CH}_{2}\right), 28.6$ $\left(\mathrm{CH}_{2}\right), 22.6\left(\mathrm{CH}_{2}\right), 14.1\left(\mathrm{CH}_{3}\right) ;{ }^{31} \mathrm{P}$ NMR $\left(\mathrm{CDCl}_{3}, 162 \mathrm{MHz}\right) \delta / \mathrm{ppm}:-17.8$ (s); IR (neat) v/cm ${ }^{-1} 3069,3054,2955$, 2921, 2831, 1585, 1569, 1419, 1252, 1240, 737, 692; HR-MS (ESI): [M + H] $]^{+} \mathrm{m} / \mathrm{z}+747.3878$, calcd. for $\mathrm{C}_{51} \mathrm{H}_{57} \mathrm{OP}_{2}: 747.3879$.

Preparation of ligand L13 Compound L13 was prepared analogously to L11 using L2 (0.7 g, 3.2 mmol), TMEDA 
(1.2 mL, $7.9 \mathrm{mmol}), n$ BuLi $(5.0 \mathrm{~mL}, 7.9 \mathrm{mmol})$ and $\mathrm{P}(p \text {-tolyl })_{2} \mathrm{Cl}(1.8 \mathrm{~mL}, 7.9 \mathrm{mmol})$ in dry hexane $(5 \mathrm{~mL})$ Yield $1.0 \mathrm{~g}(50 \%) ;{ }^{1} \mathrm{H} \mathrm{NMR}\left(\mathrm{CDCl}_{3}, 400 \mathrm{MHz}\right) \delta / \mathrm{ppm}: 7.38$ (dd, J 7.6, $\left.1.3 \mathrm{~Hz}, 2 \mathrm{H}\right), 7.17(\mathrm{~m}, 4 \mathrm{H}), 7.09$ (dquar, J 7.6, 1.7, $J(\mathrm{P}, \mathrm{H})=1.6 \mathrm{~Hz} 2 \mathrm{H}), 2.35\left(\mathrm{~s}, 12 \mathrm{H}, \mathrm{CH}_{3}-\mathrm{C}_{6} \mathrm{H}_{4} \mathrm{P}\right) .2 .09\left(\mathrm{~s}, 6 \mathrm{H}, \mathrm{CCH}_{3}\right) ;{ }^{13} \mathrm{C} \mathrm{NMR}\left(\mathrm{CDCl}_{3}, 101 \mathrm{MHz}\right) \delta / \mathrm{ppm}: 156.0(\mathrm{t}$, $J(P, C)=19.6 \mathrm{~Hz}, \mathrm{CO}), 137.9$ (phenyl C-ipso, PC), 134.0 (m, phenyl $\mathrm{CH}), 133.9\left(\mathrm{C}-\mathrm{CH}_{3}\right), 131.3(\mathrm{CH}), 131.0(\mathrm{C})$, $129.0(\mathrm{t}, J(\mathrm{P}, \mathrm{C})=7 \mathrm{~Hz}$, phenyl $\mathrm{CH}), 128.7(\mathrm{CH}), 126.4-126.2(\mathrm{~m}, \mathrm{CHC}-\mathrm{P}), 126.1$ (C) $\left.123.0 \mathrm{C}\left(\mathrm{CH}_{3}\right)_{2}\right), 122.5(\mathrm{CH})$, $\left.23.3 \mathrm{C}\left(\mathrm{CH}_{3}\right)_{2}\right), 21.3\left(\mathrm{CH}_{3}\right) ;{ }^{31} \mathrm{P}$ NMR $\left(162 \mathrm{MHz}, \mathrm{CDCl}_{3}\right) \delta:=-19.3$; IR (neat) v/cm ${ }^{-1}$ 3062, 2966, 2917, 2860, 1495, $1420,1395,1222,1183,1199,798,756,504$; HR-MS (ESI): $[M+H]^{+} m / z=511.3257$, calcd for $\mathrm{C}_{44} \mathrm{H}_{41} \mathrm{OP}_{2}$ : 511.3253.

Preparation of ligand L14 To a solution of $\mathbf{L 2}(0.6 \mathrm{~g}, 2.6 \mathrm{mmol})$ and TMEDA (1 mL, $6.6 \mathrm{mmol})$ in hexane (15 mL) at $0{ }^{\circ} \mathrm{C}, n$ BuLi $(5 \mathrm{~mL}, 7.8 \mathrm{mmol})$ was added dropwise. The red solution was left to stir overnight. At room temperature, $\mathrm{P}(t \text {-butyl })_{2} \mathrm{Cl}(1.5 \mathrm{~mL}, 7.8 \mathrm{mmol})$ was slowly added. The resulting yellow solution was warmed to $60{ }^{\circ} \mathrm{C}$ and left to stir for $24 \mathrm{~h}$. Thereafter, the solvent was removed in vacuo and the residue dissolved in DCM, shaken with water and the organic fractions were separated. After drying over anhydrous $\mathrm{MgSO}_{4}$, filtration and evaporation, the oil was washed with petroleum ether and purified by column chromatography on silica gel (hexane/EtOAc, 19:1, $\left.R_{\mathrm{f}}=0.4\right)$ to afford L14: yield: $0.3 \mathrm{~g}(20 \%) ;{ }^{1} \mathrm{H} \mathrm{NMR}\left(\mathrm{CDCl}_{3}, 400 \mathrm{MHz}\right.$ ) $\delta / \mathrm{ppm}: 7.58(\mathrm{~d}, \mathrm{~J}$ $7.6 \mathrm{~Hz}, 2 \mathrm{H}), 7.32$ (dd, J 7.5, $1.4 \mathrm{~Hz}, 2 \mathrm{H}), 7.03(\mathrm{t}, J 7.6 \mathrm{~Hz}, 2 \mathrm{H}), 2.06(\mathrm{~s}, 6 \mathrm{H}), 1.21-1.24(\mathrm{~m}, 36 \mathrm{H}) ;{ }^{13} \mathrm{C} \mathrm{NMR}\left(\mathrm{CDCl}_{3}\right.$, $101 \mathrm{MHz}$ ) $\delta / \mathrm{ppm}: 158.7(\mathrm{t}, J(\mathrm{P}, \mathrm{C})=24.4 \mathrm{~Hz}, \mathrm{CO}), 133.4(\mathrm{CH}), 129.9(\mathrm{C}), 128.6(\mathrm{CH}), 126.6(\mathrm{t}, J(\mathrm{P}, \mathrm{C})=1.9 \mathrm{~Hz}, \mathrm{C})$, $126.0(\mathrm{dd}, J(\mathrm{P}, \mathrm{C})=8.2,4.6 \mathrm{~Hz}, \mathrm{C}), 124.1(\mathrm{C}), 120.7(\mathrm{CH}), 32.6(\mathrm{dd}, J 15.4,12.9 \mathrm{~Hz}, \mathrm{C}), 30.8\left(\mathrm{t}, J 9.1 \mathrm{~Hz}, \mathrm{PC}(\mathrm{CH})_{3}\right.$, $23.3\left(\mathrm{CH}_{3}\right) ;{ }^{31} \mathrm{P}$ NMR $\left(\mathrm{CDCl}_{3}, 162 \mathrm{MHz}\right) \delta / \mathrm{ppm}: 10.7$; IR (neat) v/cm ${ }^{-1} 3065,2891,2934,2856,1473,1456$, 1390, 1360, 1219, 1176, 797, 758; HR-MS (ESI): $[\mathrm{M}+\mathrm{H}]^{+} \mathrm{m} / \mathrm{z}=223.1117$, calcd. for $\mathrm{C}_{32} \mathrm{H}_{49} \mathrm{OP}_{2}: 223.1117$.

Typical procedure for the microwave mediated oxidation of primary alcohols to aldehydes $A$ dry microwave vial under Ar gas was charged with $\left[\mathrm{Ru}(\mathrm{H})_{2}(\mathrm{CO})\left(\mathrm{PPh}_{3}\right)_{3}\right](2.3 \mathrm{mg}, 0.0025 \mathrm{mmol}, 1 \mathrm{~mol} \%)$, ligand $(0.0025 \mathrm{mmol}, 1$ mol\%), and solvent $(250 \mu \mathrm{L})$ added. The vial was sealed, and the reaction mixture microwaved for $15 \mathrm{~min}$ at 80 ${ }^{\circ} \mathrm{C}$ for complexation. Under an inert Ar atmosphere, the primary alcohol substrate $(0.25 \mathrm{mmol})$ was added, followed by crotononitrile $(31 \mu \mathrm{L}, 0.375 \mathrm{mmol})$. The reaction mixture was microwaved for a further $25 \mathrm{~min}$ at $120{ }^{\circ} \mathrm{C}$. The resultant yellow mixture was cooled, diluted with DCM and both solvents evaporated, and the sample analysed by ${ }^{1} \mathrm{H}$ NMR using an internal standard.

Typical procedure for the solvent-free microwave mediated oxidation of 1a to 2a A dry microwave vial under Ar gas was charged with $\left[\mathrm{Ru}(\mathrm{H})_{2}(\mathrm{CO})\left(\mathrm{PPh}_{3}\right)_{3}\right](6.9 \mathrm{mg}, 0.01 \mathrm{mmol}, 1 \mathrm{~mol} \%)$, ligand $13(4.89 \mathrm{mg}, 0.01 \mathrm{mmol}, 1$ mol\%), benzyl alcohol (78 $\mu \mathrm{L}, 1 \mathrm{mmol})$, and crotononitrile $(93 \mu \mathrm{L}, 1.5 \mathrm{mmol})$. The resultant mixture was microwaved for a total of $35 \mathrm{~min}$ at the specified reaction temperature $(100,120$, or $140 \mu \mathrm{C})$, and samples withdrawn every 5 min and analysed by ${ }^{1} \mathrm{H}$ NMR using an internal standard.

\section{Acknowledgements}

We thank SASOL and the NRF (Grant no. 114746) for their financial support.

\section{Supplementary Material}

General notes and NMR spectra associated to this study can be found in the supplementary materials. 


\section{References}

1. 1. Mansell, S. M. Dalton Trans. 2017, 46, 15157-15174, https://doi.org/10.1039/c7dt03395h

2. Kumar, R.; Ujjval, R.; Thirupathi, N. Eur. J. Inorg. Chem., https://doi.org/10.1002/ejic.201900616

3. Agapova, A.; Junge, H.; Beller, M. Chem. Eur. J. 2019, 25, 9345-9349, https://doi.org/10.1002/chem.201900966

4. Calleja, P.; Ernst, M.; Hashmi, A. S. K.; Schaub, T. Chem. Eur. J. 2019, 25, 9498-9503, https://doi.org/10.1002/chem.201900531

5. Liu, H. M.; Jian, L.; Li, C.; Zhang, C. C.; Fu, H. Y.; Zheng, X. L.; Chen, H.; Li, R. X. J. Org. Chem. 2019, 84, 9151-9160, https://doi.org/10.1021/acs.joc.9b01100

6. Zhao, Z. F.; Bagdi, P. R.; Yang, S.; Liu, J. G.; Xu, W. C.; Fang, X. Q. Org. Lett. 2019, 21, 5491-5494, https://doi.org/10.1021/acs.orglett.9b01789

7. Nixon, T. D.; Whittlesey, M. K.; Williams, J. M. J. Dalton Trans. 2009, 753-762, https://doi.org/10.1039/B813383B

8. Marimuthu, T.; Friedrich, H. B. ChemCatChem 2012, 4, 2090-2095, https://doi.org/10.1002/cctc.201200306

9. Marimuthu, T.; Bala, M. D.; Friedrich, H. B. J. Coord. Chem. 2013, 66, 780-788, https://doi.org/10.1080/00958972.2013.769212

10. Friedrich, H. B.; Singh, N. Tetrahedron Lett. 2000, 41, 3971-3974, https://doi.org/10.1016/s0040-4039(00)00531-1

11. Friedrich, H. B.; Khan, F.; Singh, N.; van Staden, M. Synlett 2001, 869-871, https://doi.org/10.1055/s-2001-14595

12. Tan, J.; Liu, X. B.; Chen, W. F.; Hu, Y. L. ChemistrySelect 2019, 4, 8477-8481, https://doi.org/10.1002/slct.201901690

13. Chen, T.; Xu, Z. K.; Zhou, L.; Qiu, J. Q.; Wang, M. L.; Wang, J. P. J. Mol. Catal. 2019, 474, https://doi.org/10.1016/j.mcat.2019.110422

14. Thangavel, S.; Boopathi, S.; Mahadevaiah, N.; Kolandaiyel, P.; Pansuriya, P. B.; Friedrich, H. B. J. Mol. Catal. A: Chem. 2016, 423, 160-171, https://doi.org/10.1016/j.molcata.2016.06.017

15. Dai, X. Y.; Rasamani, K. D.; Wu, S. Y.; Sun, Y. G. Mater. Today Energy 2018, 10, 15-22, https://doi.org/10.1016/j.mtener.2018.08.003

16. Jiang, Y. W.; Chai, K. J.; Wang, Y. Q.; Zhang, H. D.; Xu, W. M.; Li, W. M.; Shi, Y. F. ACS Appl. Nano Mater. 2019, 2, 4435-4442, https://doi.org/10.1021/acsanm.9b00828

17. Mori, T.; Ishii, C.; Kimura, M. Org. Prep. Proced. Int. 2019, 23, 1709-1717, https://doi.org/10.1021/acs.oprd.9b00207

18. Gichumbi, J. M.; Friedrich, H. B.; Omondi, B. Inorg. Chim. Acta 2017, 456, 55-63, https://doi.org/10.1016/j.ica.2016.11.014

19. Hamid, M. H. S. A.; Slatford, P. A.; Williams, J. M. J. Adv. Synth. Catal. 2007, 349, 1555-1575, https://doi.org/10.1002/adsc.200600638

20. Dobereiner, G. E.; Crabtree, R. H. Chem. Rev. 2010, 110, 681-703, 


\section{https://doi.org/10.1021/cr900202i}

21. Owston, N. A.; Parker, A. J.; Williams, J. M. J. Chem. Commun. 2008, 624-625, https://doi.org/10.1039/B717073D

22. Mallan, J. M.; Bebb, R. L. Chem. Rev. 1969, 69, 693-755, https://doi.org/10.1021/cr60261a006

23. Antonio, Y.; Barrera, P.; Contreras, O.; Franco, F.; Galeazzi, E.; Garcia, J.; Greenhouse, R.; Guzman, A.; Velarde, E.; Muchowski, J. M. J. Org. Chem. 1989, 54, 2159-2165, https://doi.org/10.1021/jo00270a027

24. Hillebrand, S.; Bruckmann, J.; Krüger, C.; Haenel, M. W. Tetrahedron Lett. 1995, 36, 75-78, https://doi.org/10.1016/0040-4039(94)02206-Q

25. Badejo, I. T.; Karaman, R.; Fry, J. L. J. Org. Chem. 1989, 54, 4591-4596, https://doi.org/10.1021/jo00280a026

26. van der Veen, L. A.; Keeven, P. H.; Schoemaker, G. C.; Reek, J. N. H.; Kamer, P. C. J.; van Leeuwen, P. W. N. M.; Lutz, M.; Spek, A. L. Organometallics 2000, 19, 872-883, https://doi.org/10.1021/om9907340

27. Mispelaere-Canivet, C.; Spindler, J.-F.; Perrio, S.; Beslin, P. Tetrahedron 2005, 61, 5253-5259, https://doi.org/10.1016/j.tet.2005.03.078

28. Galema, S. A. Chem. Soc. Rev. 1997, 26, 233-238, https://doi.org/10.1039/CS9972600233

29. Olofsson, K.; Larhed, M., Microwave Assisted Organic Synthesis. Blackwell Publishing Ltd: Oxford, 2005.

30. Roberts, B. A.; Strauss, C. R. Acc. Chem. Res. 2005, 38, 653-661, https://doi.org/10.1021/ar040278m

31. Keene, F. R. Coord. Chem. Rev. 1999, 187, 121-149, https://doi.org/10.1016/S0010-8545(99)00034-X

32. Baratta, W.; Bossi, G.; Putignano, E.; Rigo, P. Chem. Eur. J. 2011, 17, 3474-3481, https://doi.org/10.1002/chem.201003022

33. Asensio, G.; Cuenca, A. B.; Esteruelas, M. A.; Medio-Simón, M.; Oliván, M.; Valencia, M. Inorg. Chem. 2010, 49, 8665-8667, https://doi.org/10.1021/ic101498h

34. Hayes, B. L., Microwave Synthesis, Chemistry at the Speed of Light. CEM Publishing: Matthews, 2002; p 3935.

35. Kerton, F. M., Alternative Solvents for Green Chemistry. The Royal Society of Chemistry Cambridge, 2009; $p$ 23-24.

36. Dierkes, P.; van Leeuwen, P. W. N. M. J. Chem. Soc., Dalton Trans. 1999, 1519-1529, https:// doi.org: 10.1039/A807799A

37. van Leeuwen, P. W. N. M.; Kamer, P. C. J.; Reek, J. N. H. Pure Appl. Chem. 1999, 71, 1443-1452,

38. van Leeuwen, P. W. N. M.; Kamer, P. C. J.; Reek, J. N. H.; Dierkes, P. Chem. Rev. 2000, 100, 2741-2769, https://doi.org/10.1021/cr9902704

39. Freixa, Z.; van Leeuwen, P. W. N. M. Dalton Trans. 2003, 1890-1901, https://doi.org/10.1039/B300322C

40. Ledger, A. E. W.; Slatford, P. A.; Lowe, J. P.; Mahon, M. F.; Whittlesey, M. K.; Williams, J. M. J. Dalton Trans. 2009, 716-722, https://doi.org/10.1039/B813543F 
41. Zuidema, E.; Goudriaan, P. E.; Swennenhuis, B. H. G.; Kamer, P. C. J.; van Leeuwen, P. W. N. M.; Lutz, M.; Spek, A. L. Organometallics 2010, 29, 1210-1221, https://doi.org/10.1021/om901041r

42. Calculated by P. W. N. M. van Leeuwen using Sybyl.

43. Kranenburg, M.; Vanderburgt, Y. E. M.; Kamer, P. C. J.; van Leeuwen, P. W. N. M.; Goubitz, K.; Fraanje, J. Organometallics 1995, 14, 3081-3089, https://doi.org/10.1021/om00006a057

44. Slatford, P. A.; Whittlesey, M. K.; Williams, J. M. J. Tetrahedron Lett. 2006, 47, 6787-6789, https://doi.org/10.1016/j.tetlet.2006.07.069

45. Ahmad, N.; Robinson, S. D.; Uttley, M. F. J. Chem. Soc., Dalton Trans. 1972, 843-847, https://doi.org/10.1039/DT9720000843

This paper is an open access article distributed under the terms of the Creative Commons Attribution (CC BY) license (http://creativecommons.org/licenses/by/4.0/) 